\title{
Simplified intravenous nutrition using Intralipid-based mixtures in patients with serious gastrointestinal disease
}

\author{
W. R. BURNHAM* \\ M.D., M.R.C.P. \\ C. E. KNOTT \\ J. A. COOK \\ B.Sc., M.P.S. \\ B.Pharm., M.P.S. \\ M. J. S. LANGMAN \\ M.D., F.R.C.P.
}

University Department of Therapeutics and Department of Pharmacy, City Hospital, Nottingham, England

\begin{abstract}
Summary
An Intralipid-based intravenous feeding mixture has been given to 20 patients with serious gastrointestinal disease who required parenteral nutritional support (mean duration 13.75 days). In half of the patients, only peripheral veins were used for infusion (mean duration 12 days), the infusion site being changed every 24-48 hr. Positive nitrogen balance was maintained in all but one individual and other parameters of nutrition improved. No serious complications due to intravenous feeding were encountered, although some patients did develop abnormal liver function tests and mild phlebitis at the peripheral vein infusion site. No abnormalities of pulmonary gas exchange attributable to the infusion were noted.

We conclude that this mixture is safe, relatively simple to use and effective. Consequently, it may be especially appropriate for patients in general medical and surgical wards as well as those in specialist units.
\end{abstract}

KEY WORDS: intravenous nutrition, Intralipid mixtures.

\section{Introduction}

Intravenous feeding is recognised as valuable in patients unable to take nourishment by mouth or nasogastric tube. The feeds are usually administered via a subclavian catheter which requires skilful placement. The risks of insertion and infection of the catheter are well recognised, so some hospitals employ a peripatetic team of experts to manage their patients (Powell-Tuck et al., 1978; Fischer, 1977).

Peripheral veins may be used for intravenous nutrition if lipid emulsions such as Intralipid (Kabi Vitrum Ltd) rather than dextrose are used as the major calorie source. This also reduces the risk of hyperglycaemia during infusion, but it has been

\footnotetext{
*Present address: Oldchurch Hospital, Romford, Essex RM7 0BE
}

assumed that the fat emulsion must be kept separate from other infusates. The infusion of more than one $\omega$ bottle simultaneously or sequentially complicates nursing procedures, makes errors more likely and makes it difficult to ensure the administration of a balanced regime.

In this paper, we describe the use of an Intralipid- $\overparen{\Phi}$ based intravenous feed made up in a single 3 litre bag $\overrightarrow{0}$ and infused over $24 \mathrm{hr}$. The stability of the mixture measured by physical tests has been reported els where (Burnham et al., 1983). This feed can be give through peripheral veins, and appears safe and effective in achieving positive nitrogen balance.

\section{Materials and methods}

\section{Intravenous feeding mixture}

Intralipid $(20 \%)$ was mixed with dextrose $(10 \%)$ electrolytes and amino acid glucose solution (Vamin glucose) under laminar flow conditions in the Sterile Product Unit of Nottingham City Hospital Pharmacy. The composition of a typical feed is given in Table 1; the feed was designed to meet the needs of patients with diarrhoea or fistula losses. Patients with other conditions might need less potassium. The calcium and phosphate ion concentrations were well below the point at which precipitation would be likely (Nedich, 1977). Further unpublished work N confirms that this does not occur (Davis, personal communication, 1982).

Less nitrogen or electrolyte was given if clinically appropriate and all ingredients were mixed in a three litre bag (Travenol Laboratories Ltd.). In some instances 2000 i.u. heparin was added because it was thought possible that it might reduce the frequency of deep vein thrombosis and pulmonary embolism (Negus et al., 1980) and increase the survival of peripheral veins (Stradling, 1978). It might also 
slightly improve the stability of the emulsion mixture (Kawilarang, Georghiou and Groves, 1980).

\section{Patients studied (Table 2)}

These were patients with severe alimentary disease in need of intravenous nutritional support. Infusions were made through peripheral veins whenever possible. Nitrogen balance was calculated from daily blood and urinary area measurements (Lee and Hartley, 1975) using standard techniques. Stool losses were not measured, but only two of the patients with active inflammatory bowel disease likely to cause such significant losses (as opposed to structural disease such as obstruction) were studied before surgical treatment. Even in these two patients ( 2 and 7, Table 2) stool nitrogen losses were unlikely to exceed 4 g/day (Buckell et al., 1977). Patients were usually weighed daily and blood was taken for regular biochemical and haematological measurements; this included an anti-Factor $\bar{X}$ assay (Sigma Ltd.) in those given heparin, this being the best method available for measuring small amounts of the anticoagulant. Arm muscle bulk was measured in 10 patients by comparing triceps fat fold (estimated with calipers) and arm circumference (Gurney and Jelliffe, 1973).

Intralipid-induced hyperlipidaemia has been reported to cause abnormalities of pulmonary diffusion in adults (Greene, Haslett and Demaree, 1976) and lung damage in premature babies (Levine, Wigglesworth and Desai, 1980). Other workers have not found this (Wilmore, Moyland and Helmkamp, 1973), but as large or aggregated fat particles in the emulsion mixture might, in theory, block pulmonary capillaries, single breath carbon monoxide transfer factor analyses were made. Blockage of pulmonary capillaries would lead to decrease in alveolar capillary blood volume and thus pulmonary diffusing capacity. Transfer factor is a measure of pulmonary diffusion capacity. The single breath technique requires little patient compliance and seemed most appropriate for these patients. The measurements were performed during and before or after treatment, whenever patients were well enough to travel to the lung function laboratory. A Transfer Test Model B instrument with valve box (Morgan Ltd.) was used and a correction was made for changes in haemoglobin concentration (Cotes, 1975).

The project was approved by the North Nottingham District Hospitals Ethical Committee.

\section{Results}

Twenty patients (12 of whom had inflammatory bowel disease with complications requiring surgery) (Table 2) received infusates of mixed nutrients for an average of 13.75 days each (range 8-23 days); in 10 of
TABLE 1. Typical intravenous feed used in this study

\begin{tabular}{ll}
\hline Intralipid 20\%* & 1 litre \\
Vamin glucose* & 1.5 litres \\
Dextrose 10 & 0.5 litres \\
Potassium chloride & $54 \mathrm{mmol}$ \\
Potassium dihydrogen phosphate & $30 \mathrm{mmol}$ \\
Sodium chloride (as $30 \%$ solution) & $51.3 \mathrm{mmol}$ \\
Addamel* & $10 \mathrm{ml}$ \\
Vitlipid* $\dagger$ & $1 \mathrm{vial}$ \\
Solivito*† & $1 \mathrm{vial}$ \\
$\quad$ Provides: & \\
2800 non-protein kcal & $14.1 \mathrm{~g} \mathrm{nitrogen}$ \\
126.3 mmol sodium & $114 \mathrm{mmol}$ potassium \\
30 mmol phosphate & 8.75 mmol calcium \\
3.75 mmol magnesium & Trace elements \\
Vitamins & \\
\hline
\end{tabular}

*Kabi Vitrum Ltd.; †Vitamins were omitted from feeds prepared on Fridays for use on Saturday and Sunday.

Feeds containing vitamins were stored at $4^{\circ} \mathrm{C}$ for no longer than $12 \mathrm{hr}$ before commencement of infusion. Weekend feeds (without vitamins) were stored for no longer than $48 \mathrm{hr}$ at $4^{\circ} \mathrm{C}$. These procedures were based on the results of physiochemical studies reported elsewhere (Burnham et al.. 1983).

these patients only peripheral veins were used (mean duration 12 days, range 8-18 days), the infusion site being changed every 24-48 hr. Positive nitrogen balance as measured in this study was maintained in all but one individual (M.H.) (Fig. 1), although many were very ill (Table 2). Even assuming the most severe stool nitrogen loss of $4 \mathrm{~g} /$ day, of those with acute inflammation studied before surgery only one other patient (D.P.) would have been in deficit. This in itself is unlikely, as he gained $4 \mathrm{~kg}$ in weight and increased his serum albumin from $14 \mathrm{~g}$ /litre to 21 $\mathrm{g} /$ litre during intravenous feeding. The mean arm muscle area (in the 10 patients measured), mean weight and mean serum albumin tended to increase during the period of intravenous feeding. The differences were not statistically significant; the study period was probably too short to show this (Table 3). The weight and serum albumin measurements were subject to some distortion because initially oedematous patients lost weight during intravenous feeding and dehydrated patients showed a fall in serum albumin when this was corrected by infusion.

No patient showed clinical evidence of adverse effects, hyperglycaemia did not occur and serum triglyceride levels never rose above $2 \mathrm{mmol} / \mathrm{litre}$. Transfer factor did not deteriorate as a consequence of the infusion in the 12 patients studied (Fig. 2). Abnormal liver function tests developed in 9 patients during feeding, changes consisting of an elevated alkaline phosphatase ( 5 patients), and glutamyl transpeptidase (8 patients), serum glutamate pyruvate transferase ( 3 patients) and serum bilirubin ( 2 patients). In no case was it necessary to discontinue intravenous feeding, and all tests returned to normal after intravenous feeding had ceased. 


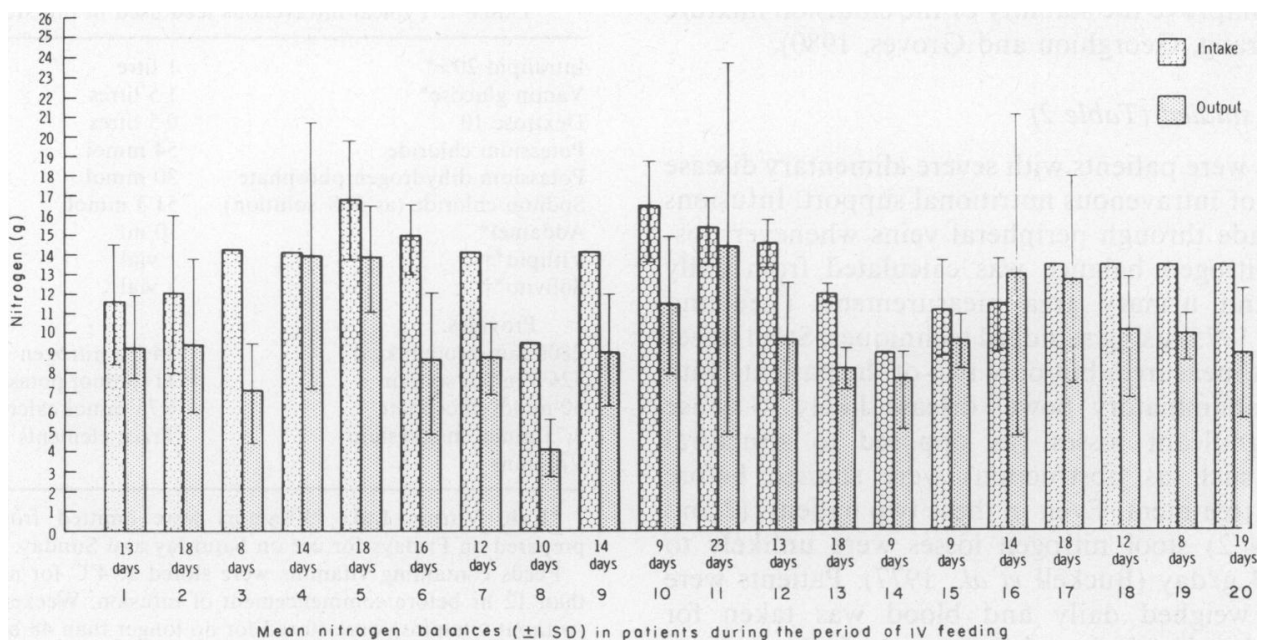

FIG. 1. Nitrogen balances in 20 patients during the period of intravenous feeding (mean \pm standard deviation). Where no standard deviation is shown, the intake/output was constant.

TABLE 2. Details of patients fed intravenously with Intralipid emulsion mixtures

\begin{tabular}{ccclcc}
\hline Patient & $\begin{array}{c}\text { Age } \\
\text { (years) }\end{array}$ & Sex & Diagnosis & $\begin{array}{c}\text { Before } \\
\text { surgery }\end{array}$ & $\begin{array}{c}\text { After } \\
\text { surgery }\end{array}$ \\
\hline 1 & 25 & F & Toxic dilatation of colon & - & + \\
2 & 29 & M & Severe Crohn's colitis with bilateral psoas abscesses & + & + \\
3 & 21 & F & Extensive small bowel Crohn's disease & - & + \\
4 & 57 & F & Toxic dilatation of colon and perforation & + & + \\
5 & 36 & F & Ulcerative colitis and obstructing colonic carcinoma & + \\
6 & 22 & M & Extensive small bowel Crohn's disease & + \\
7 & 28 & M & Severe Crohn's colitis & + & + \\
8 & 36 & F & Ileo-caecal Crohn's disease & + & + \\
9 & 54 & F & Crohn's disease & + & + \\
10 & 38 & M & Crohn's disease & - & + \\
11 & 67 & F & Severe colonic Crohn's disease + malnutrition & + \\
12 & 42 & F & Crohn's disease & + \\
13 & 62 & F & Post-colonic carcinoma resection + malnutrition & + \\
14 & 47 & M & Carcinoma of the stomach & + \\
15 & 42 & M & Pancreatitis and intestinal obstruction & + \\
16 & 85 & F & Traumatic oesophageal tear, mediastinal abscess & + \\
17 & 53 & M & Carcinoma of rectum, wound dehiscence & + \\
18 & 66 & F & Intestinal obstruction. Diverticular disease + paracolic abscess & + \\
19 & 34 & M & Post-gastrectomy + pelvic abscess & + & + \\
20 & 80 & F & Pyloric obstruction & + \\
\hline
\end{tabular}

TABLE 3. Changes in measurements of nutritional status before and after intravenous feeding

\begin{tabular}{|c|c|c|c|}
\hline & Before & After & s.e.d. \\
\hline Mean arm muscle area $\left(\mathrm{cm}^{2}\right)$ & $32 \cdot 60$ & $34 \cdot 75$ & $2 \cdot 17$ \\
\hline Mean serum albumin (g/litre) & 23.45 & $25 \cdot 60$ & 1.70 \\
\hline Mean weight (kg) & 51.55 & $52 \cdot 60$ & 2.49 \\
\hline
\end{tabular}

s.e.d. $=$ standard error of difference.

Some 'creaming' of the emulsion (Burnham et al., 1983 ) in the 3 litre bag was seen after the infusion had been running for $16-18 \mathrm{hr}$, but was easily reversed by gentle squeezing of the bag and did not recur in the $N$ remaining 6-8 $\mathrm{hr}$. Heparin activity in plasma never exceeded $0.03 \mathrm{U} / \mathrm{ml}$ in those who received this agent. No patient developed deep vein thrombosis, pulmo- $\omega$ nary embolism or bleeding problems during surgery while feeds containing heparin were being infused. Five patients did develop mild phlebitis at the drip $\mathbb{\Phi}$ site, but this was rarely a difficulty provided the cannula was resited regularly in a large arm vein, and drugs likely to cause phlebitis were not given by the same route. 


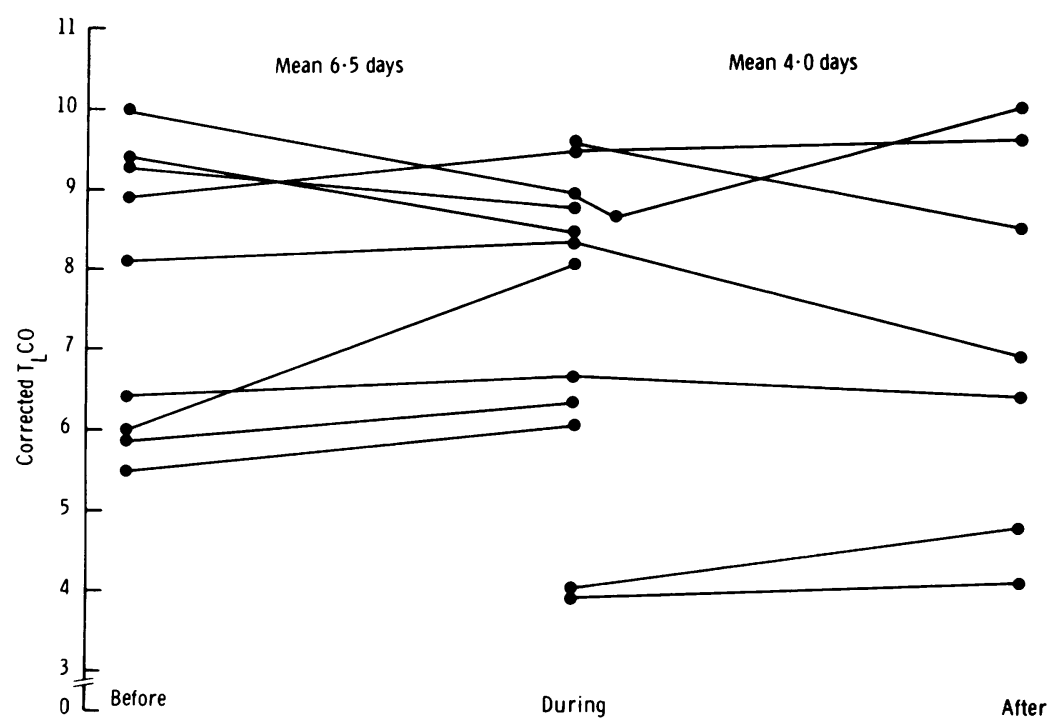

FIG. 2. Single breath carbon monoxide transfer factor on and off intravenous feeding in 12 patients. The mean in days refers to (a) average time from commencement of feeding to measurement or (b) average time from cessation of feeding to measurement.

\section{Discussion}

Our results show that certain mixtures of Intralipid can be safely mixed in a 3 litre bag and infused via peripheral veins. The advantages of such a system over infusions into a central line or multiple bottle infusions are considerable. It requires less nursing time, can be easily managed in a busy general ward, ensures administration of a balanced regime and avoids the problems associated with central vein catheter insertion and maintenance. There was an increase in the pharmacy work load during the week, but no increase in weekend working, as bags were made up in advance on Fridays. Thus any increase in work was managed in normal working hours and the nursing problems which may previously have occurred at night are greatly reduced. Most Districts now have Laminar air flow units and the remainder are likely to obtain them in the future.

The problem of hyperglycaemia seen with dextrose based solutions is also avoided, even in those patients whose poor peripheral veins mean a central line must be used for long-term feeding.

Despite the simplicity of the method, adequate nutritional support can be provided for ill patients. Within the limits of the mixtures tested, the intake of energy, nitrogen and electrolytes can be adjusted to the needs of each patient. Clearly, further studies are required to define other mixtures which may be safely used. However, our results agree with clinical studies performed in France (Solassol and Joyeux, 1974), where an Intralipid-based feeding mixture has been used successfully for some years. There is evidence that a combination of fat and carbohydrate calories is to be preferred as an energy source in intravenous nutrition (Lee, 1977; Askanazi et al., 1980; Macfie, Smith and Hill, 1981; Kirkpatrick, Dahn and Lewis, 1981).

Creaming of the emulsion during infusion, presumably due to the presence of aggregated particles, was easily reversed by gentle shaking. This did not recur during the infusion and did not pose a clinical or pharmaceutical problem.

Abnormal liver function tests were noted in 9 of the patients. However, this is a recognised complication of intravenous and nasogastric tube feeding (Tweedle et al., 1979), and did not occur more frequently than would be expected; in no case did it necessitate a cessation of the treatment, and no other adverse effects were noted. It was reassuring that no patient developed symptoms of fat embolism in the lungs and that no significant deterioration was detected in measurements of transfer factor during infusion. No patient developed clinical evidence of deep vein thrombosis or pulmonary embolism and no bleeding problems were encountered in 2 patients who underwent surgery during infusion of heparincontaining feeds. Minor phlebitis occurred at the drip sites in some patients, especially if certain antibiotics were administered also, but careful placement and regular changing of the cannula avoided serious problems.

We conclude that this relatively simple method of intravenous feeding is both safe and effective in clinical practice. However, until further pharmaceutical and clinical studies have been performed, only those Intralipid mixtures which have been tested can 
be recommended for use. Particular care is required in those with higher concentrations of divalent cations (Burnham et al., 1983). Further experience with this method of intravenous feeding confirms the clinical benefit reported in this paper. We are now examining other amino acid solutions to assess their suitability for mixing with Intralipid.

\section{Acknowledgments}

We wish to acknowledge the help of our clinical colleagues who allowed us to study patients under their care. Dr A. M. J. Woolfson and Dr P. A. Jones provided biochemical and haematological advice and assistance, and $\mathrm{Mr}$ J. Gilby pharmaceutical expertise. Professor P. Fentem gave the advice about lung function tests and measurements of transfer factor were performed by $\mathrm{Mr} \mathrm{S}$. Harrison and the staff of the lung function laboratory. The nursing staff in all wards were most helpful. We wish to thank Kabi Vitrum Ltd. for financial support.

\section{References}

Askanazi, J., Carpentier, Y.A., Elwyn, D.H., Nordenstrom, J., JeEvanandaM, M., Rosenbaum, S.H., Gump, F.E. \& KinNEY, J.M. (1980) Influence of total parenteral nutrition on fuel utilization in injury and sepsis. Annals of Surgery, 191, 40.

Bucknell, N.A., Gould, S.R., Hernandez, M.A., Kohn, J., Lennard-Jones, J.E., Powell-TuCK, J., Riches, P.G. \& WELCH, S.G. (1977) Direct method of measuring faecal protein loss in patients with ulcerative colitis. Gut, 18, 971.

Burnham, W.R., HansRani, P., KNotT, C.F., CoOK, J.A. \& Davis, S.S. (1983) Stability of a fat emulsion based intravenous feeding mixture. International Journal of Pharmaceutics, 13, 9.

COTES, J.E. (1975) Lung function: assessment and application in medicine, 3rd edn, p. 238. Blackwell Scientific Publications. Oxford, England.

FISCHER, J.E. (1977) The organisation of a hyperalimentation unit. In: Current concepts in parenteral nutrition (Eds. J. M. Greep, P. B. Soeters, R. I. C. Wesdorp, C. W. R. Phaf \& J. E. Fischer), p. 77. Martinus Nijhoff, The Hague.

Greene, H.L., Hazlett, D. \& Demaree, R. (1976) Relationship between Intralipid-induced hyperlipidaemia and pulmonary function. American Journal of Clinical Nutrition, 29, 127.

GuRNeY, J.M. \& Jelliffe, D.B. (1973) Arm antropometry in nutritional assessment: Program for rapid calculation of muscle circumference and cross-sectional muscle and fat areas. American Journal of Clinical Nutrition, 26, 912.

Kawilarang, C.R.T., Georghiou, K. \& Groves, M.J. (1980) The effect of additives on the physical properties of a phospholipid:stabilised soya bean oil emulsion. Journal of Clinical and HospitaEs Pharmacy, 5, 151.

KIRKPATRICK, J.R., DAHN, M. \& LEWIS, L. (1981) Selective versu유 standard hyperalimentation. A randomised prospective study음 American Journal of Surgery, 141, 116.

LEE, H.A. (1977) The rationale for using a fat emulsion ('Intralipid' as part energy substrate during intravenous nutrition. In: Curren 2 concepts in parenteral nutrition. (Eds. J. M. Greep. P. B. Doeters, $\mathrm{R}$ I. C. Wesdorp, C. W. R. Phaf \& J. E. Fischer), p. 261. Martinus
Nijhoff, The Hague.

LEE, H.A. \& HARTLEY, T.P. (1975) A method of determining dailynitrogen requirements. Postgraduate Medical Journal, 51, 441. $\vec{\omega}$

LeVine, M.I., Wigglesworth, J.S. \& DeSaI, R. (1980) Pulmonaryo fat accumulation after Intralipid infusion in the pre-term infan Lancet, ii, 815.

MACFIE, J., SMITH, R.C. \& HiLl, G.L. (1981) Glucose or fat as non-protein energy source? A controlled clinical trial in gastroen terological patients requiring intravenous nutrition. Gastroentero 0 $\log y, 80,103$.

NEDICH, R.L. (1977) The compatibility of extemporaneously adde drug additives with Travasol (amino acid) injection. In: Advances/ in Parenteral Nutrition (Ed. I. D. A. Johnston), Ch. 27. M.T.P.
Press, Lancaster.

Negus, D., Friedgood, A., Cox, S.J., PeEl, A.L.G. \& Wells, B.W.(1980) Ultra-low dose intravenous heparin in the prevention of postoperative deep vein thrombosis. Lancet, i, 891.

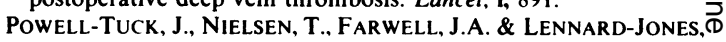
J.E. (1978) Team approach to long term intravenous feeding in patients with gastrointestinal disorders. Lancet, ii, 825 .

Solassol, C. \& JoYeuX, H. (1974) Nouvelle techniques pingew nutrition parenterale chronique. Annals de l'Anaesthesiolgitio Francaise, Special '2', 75.

STRADlinG, J.R. (1978) Heparin and infusion phlebitis. British Medical Journal, 2, 1195.

TWEedLE, D.E.F., SKIDMORE, F.D., Gleave. E.N., KNASS, D.A. \& GowLAND, E. (1979) Nutritional support for patients undergoingD surgery for cancer of the head and neck. In: Johnson, I.D.A., Lee, H.A.. Eds. Developments in Clinical Nutrition. (Eds. I. D. A. $\overrightarrow{\bar{O}}$ Johnson \& H. A. Lee), p. 59. Medical Congresses and Symposia 3 Consultants, Tunbridge Wells, England.

Wilmore, D.W., Moyland, J.A. \& Helmkamp. G.M. (1973) Clinical evaluation of a $10 \%$ intravenous fat emulsion for parenteral nutrition in thermally injured patients. Annals of을 Surgery, 178, 503. 